\title{
EFFECT OF DIFFERENT ETCHING TIMES ON SEALANT PROPERTIES APPLIED TO FLUORIDE TREATED TEETH: AN IN VITRO STUDY
}

\author{
Rabaa Mahmoud Abo-Bakr*
}

\begin{abstract}
This study aimed to investigate the effect of fluoride varnish on microleakage and the interfacial micromorphology of pit and fissure nano sealant after different etching times.

Materials and methods: One hundred freshly extracted third molars were used in this study. They were randomly allocated into control group (20 teeth) and test group (80 teeth) which was further subdivided into 4 subgroups each one contained (20 teeth) according to the etching time. Teeth of the test group were subjected to fluoride varnish application. The next day, each subgroup was acid etched according to its specific time (20, 40, 60, and 120 seconds for groups I, II, III and IV respectively). Nano fissure sealant was then applied to all teeth according to the manufacturer instructions. Teeth in the control group received the nano sealant without fluoride application. Ten teeth from each subgroup were used for interfacial micromorphology scanning, and the other 10 teeth were used for microleakage evaluation.
\end{abstract}

Results: The scanning electron microscopic examination revealed that the formed tags varied between the groups. The shortest tags were found in subgroup I (between 2.24-3.22 $\mu \mathrm{m}$ ), while the largest were in subgroup IV (35.19-35.24 $\mu \mathrm{m})$. Score 0 microleakage was the significantly highest one in all groups. The comparison between test groups and control group revealed significant differences in score 1 and 3 only.

Conclusion: Application of fluoride did not affect the sealant application especially for the etching times 40 and 60 seconds.

KEY WORDS: Fluoride varnish - Nano sealant - Etching time.

\section{INTRODUCTION}

Caries prevalence has been reduced in most industrialized countries. However, dental caries is still a problem in some populations. It was reported to have increased prevalence in some developing countries $^{(1,2)}$.In Egypt, caries prevalence was measured at different governorates since 1962 . About $81.4 \%$ of the $6-19$ years studied population had caries $^{(3)}$. In a more recent study, this percentage did not differ a lot as $77 \%$ of the examined 12 years old children in Demietta governorate had caries ${ }^{(4)}$.

\footnotetext{
* Lecturer of Dental Public Health and Preventive Dentistry, Faculty of Dentistry, Mansoura University.
} 
But later on, this percentage much decreased as it was $(40.9 \%$, and $39.4 \%$ for female and male subjects of the same age respectively) in Mansoura city at $2012^{(5)}$.

The majority of the detected caries among children and adolescents was reported to affect the pit and fissure surfaces of first molars ${ }^{(6)}$. This caries pattern advocates the utilization of some preventive measures like fissure sealants and topical fluoride application.

Dental sealants are resin materials that are used to physically seal deep pits and fissures preventing the accumulation of plaque and food debris in such areas, thus reducing caries. The success of the sealants depends on the proper enamel etching ${ }^{(7)}$.

Fluoride is one of the most commonly used caries preventive measures. It is reported to reduce caries and plaque accumulation both in children and adults ${ }^{(8,9)}$. In 2001, Whelton recommended the combined use of fluoride and sealants as caries preventive measures ${ }^{(10)}$.

Although fluoride is reported to reduce the enamel solubility in acidic conditions, its effect on resin or sealant attachment is still argued. Wang and Sheen ${ }^{(11)}$ reported that fluoride application before acid etching has no effect, while, Meng et $\mathrm{al}^{(12)}$ reported that it influences the enamel etching prior to resin application. Later on, the application of fluoride varnish was reported to have no effect on the shear bond strength of orthodontic brackets to enamel ${ }^{(13)}$. In another study, it was concluded that the proper sealant retention is obtained when the acid etching step was done two weeks after fluoride application. Moreover, to apply the sealant before two weeks, the etching time should be increased ${ }^{(14)}$.

Several studies recommended that fluoridated enamel should be etched for longer times that ranged from $75-180$ seconds instead of the conventional time of $15-20$ seconds $^{(15,16)}$. These results were supported by the scanning electron microscope and enamel topography changes studies ${ }^{(17)}$.
There is a controversy about the effect of fluoride on the retention of pit and fissure sealant, so this study aimed to investigate the effect of fluoride varnish on microleakage and the interfacial micromorphology of pit and fissure nano sealant after different etching times.

\section{MATERIALS AND METHODS}

100 sound permanent molars extracted due to impaction were selected. The teeth were cleaned and disinfected in $0.5 \%$ chloramines solution for $24 \mathrm{~h}$, then stored in normal saline at $37^{\circ}$ till the time of use. Prophylaxis was done for all teeth using pumice and brush at low speed. Excess of pumice powder was then removed by moving fine explorer on pits and fissures' base. Teeth were randomly allocated into two main experimental groups; test group (received fluoride varnish before sealant application) and control group (sealant was applied without fluoride). In the test group (80 teeth) the etching was done one day after fluoride application. The teeth were divided into 4 subgroups (20 teeth each) according to the etching time as follows; subgroups I, II, III, and IV where the enamel was etched for 20,40,60, and 120 seconds respectively. In control group (20 teeth) sealant was applied without fluoride application according to the manufacturer instructions ${ }^{(18)}$. Ten teeth from each subgroup were used for scanning electron microscope and the other ten teeth were used for microleakage testing.

\section{Technique of application}

Fluoride varnish (Duraphat varnish, 5\% $\mathrm{NaF}=2.26 \% \mathrm{~F}$, Colgate-Palmolive, Germany) was applied using paint on technique ${ }^{(19)}$. After dryness of the varnish the teeth were stored in artificial saliva to the next day. Teeth were air dried and subjected to sealant application according to their groups. All teeth were acid etched by phosphoric acid 37\% (H3PO4, FineEtch 37, Spident Inc., Korea). Nanofilled resin based fissure sealant (GrandioSeal, Voco, Cuxhaven, Germany) was then applied to the teeth according to the manufacturer instructions. All 
teeth were stored in artificial saliva till scanning and microleakage tests were performed.

\section{Scanning electron microscope}

\section{Interfacial micromorphology evaluation}

Sectioned teeth were examined by scanning electron microscope (SEM). The sections were polished with a 600 -grit abrasive paper. The polished surfaces were etched for 20 seconds with $37 \%$ phosphoric acid to remove the smear layer followed by deproteinization in 5\% sodium hypochlorite for 5 min. after being rinsed with distilled water, each sample was mounted on stubs, sputter coated with gold and examined with SEM ${ }^{(20)}$.

\section{Microleakage}

In preparation for dye penetration (leakage) test, the crowns were coated with two layers of nail polish interposed by a layer of wax, leaving exposed a $1.5-\mathrm{mm}$ window around the sealant margins and immersed in $2 \%$ buffered methylene blue dye for $24 \mathrm{~h}$. Thereafter, the nail varnish and wax were removed with a sharp instrument. After that the teeth/resin blocks were sectioned longitudinally in buccolingual direction with a water-cooled slow speed operated diamond coated disc (Buehler, USA) thus providing 2 sections per tooth. The sections were examined with USB digital microscope (Scope Capture Digital Microscope, Guangdong, China) at $65 \mathrm{x}$ magnification and photographed using image analysis software (Image-J 1.45K, National Institute of Health, USA) and a ranked scale was used to score dye penetration as follows: ${ }^{(21,22)}$.

$0=$ no dye penetration;

$1=$ dye penetration limited to the outer half of the sealant;

$2=$ dye penetration extending to the inner half of the sealant;
$3=$ dye penetration extending to the underlying fissure.

\section{Statistical Analysis}

Statistical analyses were performed using Statistical Package for Social Sciences (SPSS), software for Windows version 17. Data from microleakage scores were collected and expressed as numbers and percentages. Chi-square test was used for statistical analysis and the significance level was considered at $5 \%$.

\section{RESULTS}

\section{Electro-Microscopic results}

The scanning electron microscopic examination revealed that the sealant in all groups was in close contact with the enamel surface. However, the formed tags varied between the groups. They were very short in subgroup I and accordingly the sealant penetrated these tags to a short distance that ranged between 2.24-3.22 $\mu \mathrm{m}$. For subgroup II, the scanning results showed that when enamel was etched for 40 seconds, the formed enamel tags ranged between 7.24- $10.24 \mu \mathrm{m}$. In subgroup III, the formed enamel tags were $25.47-34.14 \mu \mathrm{m}$. On the other hand, the formed enamel tags in subgroup IV ranged between 35.19- $35.24 \mu \mathrm{m}$.

\section{Microleakage results}

Table (1) showed that score 0 was the significantly highest one in all groups, while score 2 was not found in any group. Score 1 was not found in control group. However score 3 was found in control group and subgroups I and II. Significant differences were found in each subgroup between different scores. The comparison between test groups and control group revealed significant differences in score 1 and 3 only. 


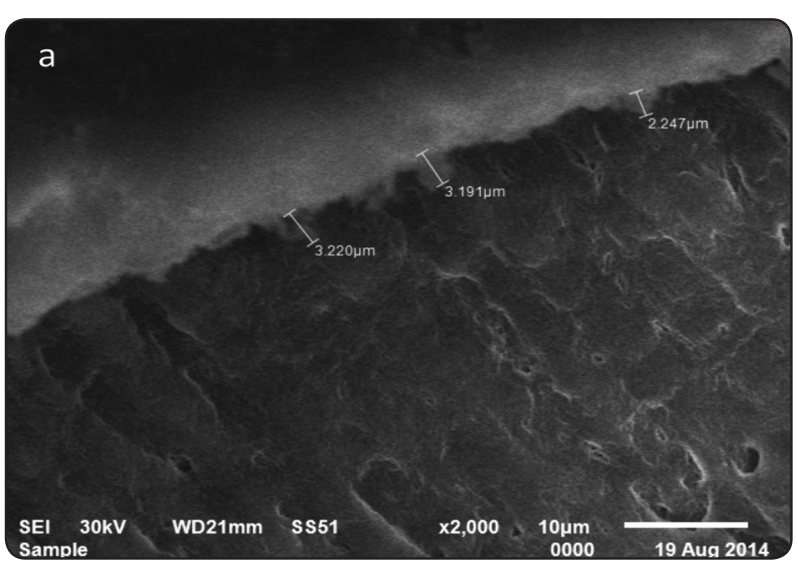

Fig. (a) Micrograph of a sample in subgroup I showing that sealant enters the very short enamel tags.

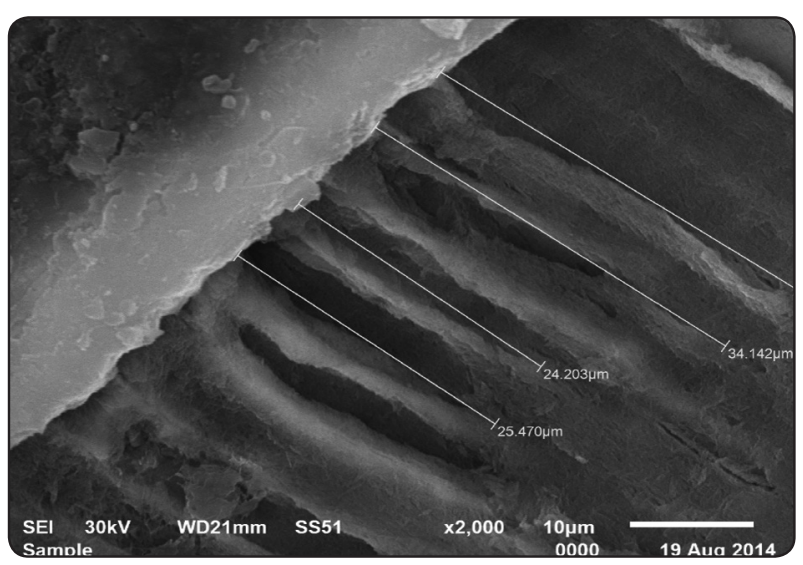

Fig. (c) Micrograph of a sample in subgroup III showing that sealant enters the enamel pores that ranged from 25.47-34.14 $\mu \mathrm{m}$.

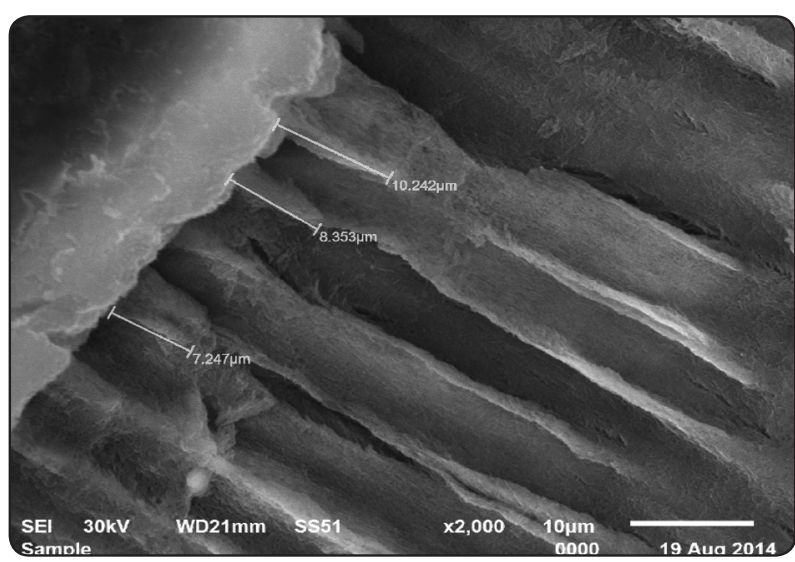

Fig. (b) Micrograph of a sample in subgroup showing that the sealant enters more elongated enamel pores.

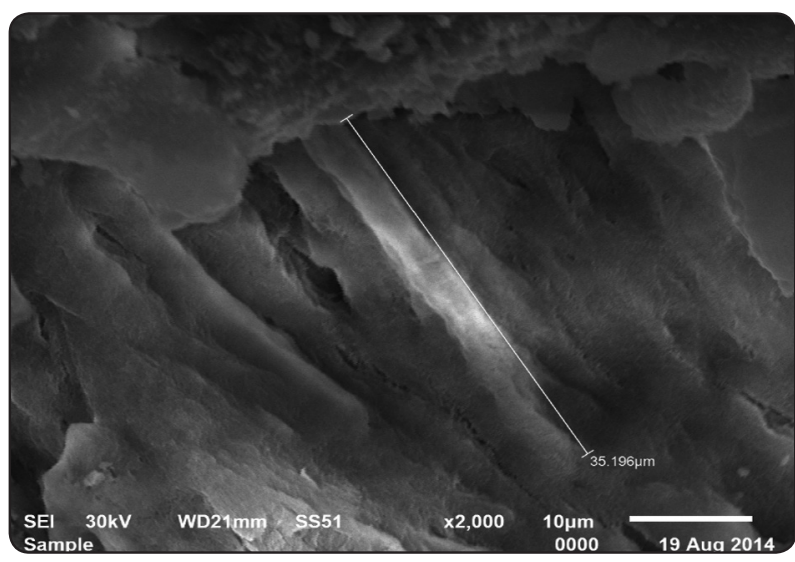

Fig. (d): Micrograph of a sample in subgroup IV showing the greatest sealant penetration into enamel pores.

TABLE (1) Effect of fluoride application on microleakage of pit and fissure sealant through different etching times.

\begin{tabular}{|c|c|c|c|c|c|c|c|}
\hline \multirow{2}{*}{\multicolumn{2}{|c|}{ Groups }} & \multicolumn{4}{|c|}{ Scores } & \multirow{2}{*}{$\begin{array}{c}\text { Chi square } \\
\text { test }\end{array}$} & \multirow{2}{*}{ p-value } \\
\hline & & 0 & 1 & 2 & 3 & & \\
\hline \multirow{4}{*}{ Test } & Subgroup I & $6(60 \%) \mathrm{Abc}$ & $2(20 \%)$ ad $€$ & 0 bde & $2(20 \%)$ ce€\# & 57.29 & $0.00^{*}$ \\
\hline & Subgroup II & $7(70 \%) \mathrm{Abc}$ & $1(10 \%) \operatorname{ad} \subset$ \# & 0 bde & $2(20 \%)$ ce $\mathbb{C} \&$ & 81.66 & $0.00^{*}$ \\
\hline & Subgroup III & $7(70 \%) \mathrm{Abc}$ & $3(30 \%)$ ade $\subset \&$ & $0 \mathrm{Bd}$ & 0 ce $€(\mathbb{C} \bullet$ & 98.41 & $0.00^{*}$ \\
\hline & Subgroup IV & $8(80 \%) \mathrm{Abc}$ & $2(20 \%)$ Ade• & $0 \mathrm{Bd}$ & 0 ce\#\&® & 118.05 & $0.00^{*}$ \\
\hline Control & Control & $9(90 \%) \mathrm{Abc}$ & $0 \mathrm{ad} € \# \& \bullet$ & $0 \mathrm{Be}$ & $1(10 \%) \mathrm{cde} \bullet \circledR$ & 147.12 & $0.00^{*}$ \\
\hline \multicolumn{2}{|c|}{ p-value } & 0.406 & $0.00 *$ & - & $0.00^{*}$ & & \\
\hline
\end{tabular}

The same letters indicate significant differences between the scores within the same group

Same symbols indicate significant differences between the groups within the same score.

* Statistical significant difference at $\mathbf{p} \leq \mathbf{0 . 0 5}$ 


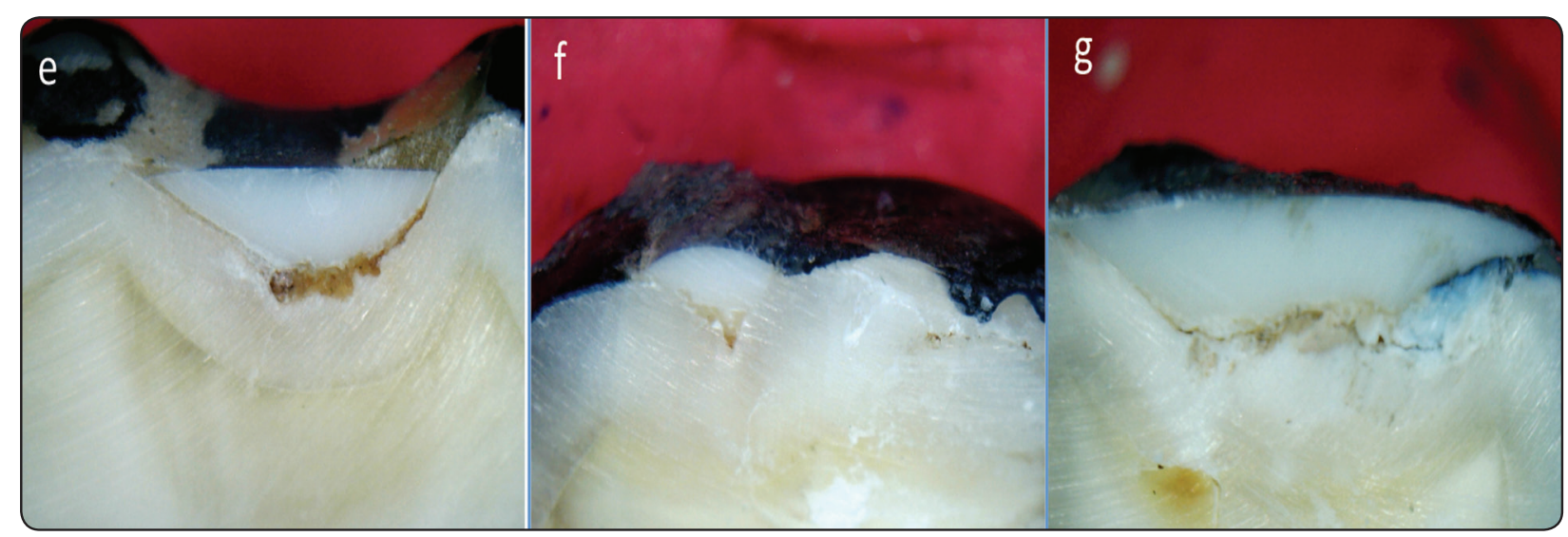

Fig. (e) Microleakage score 0

Fig. (f) Microleakage score 1

Fig. (g) Microleakage sore 3

\section{DISCUSSION}

It was known that addition of fluoride to a sealant, or to the enamel prior to sealant application could have the benefit of additional caries prevention. Also it reduces the solubility of enamel without compromising sealant properties. ${ }^{(23)}$

Fluoride forms calcium fluoride, which affects the attachment of acid etching or sealant application. It was reported that an APF pretreatment led to decreased surface roughness in the acid-etched enamel in both the primary and permanent teeth. After the APF treatment, the more roughness of both the primary and permanent teeth increased with increasing time elapsed. Therefore, acid-etching should be performed two weeks after fluoride application to achieve the maximum enamel adhesion of a sealant. Prolonged acid-etching time (40 s) showed increased nanostructural changes in the enamel surfaces regardless of the time elapsed after the APF pre-treatment compared to the groups etched for $20 \mathrm{~s}$. This suggests that after the APF treatment, even if two weeks have not elapsed, a prolonged acid-etching time can induce high surface roughness ${ }^{(14)}$. Therefore this study was performed to evaluate the effect of fluoride varnish application on acid etching before sealant application.

The results of the present study indicated that fluoride application prior to acid etching significantly affected the length of the formed enamel tags in the different groups with subgroup I being the least formed tags and nearly comparable tags in subgroups III and IV. Group IV showed the tallest formed enamel tags. These results indicated that the effect of fluoride on enamel etching decreased by increasing the etching time and it may resemble non fluoridated enamel after 60-120 seconds. Many previous studies reported that the effect of fluoride decreases with time although they reported that the enamel retained its normal etching pattern after different periods that ranged from $60 \mathrm{sec}$ up to 4 minutes ${ }^{(14-17,24,25)}$. The variation in time elapsed till the etched enamel returns to the non-fluoridated pattern may be attributed to the difference in the etching agents and the concentration of the agent used. Additionally, the fluoride agents used in these studies may also contribute to the difference in variation in the etching time. Most of these studies used (APF) acidulated phosphate fluoride gel or sodium fluoride solution, while in this study we used Duraphat fluoride varnish. There are no in reach studies that used fluoride varnish before sealant application to compare the results.

The scanning examination revealed that sealant in all subgroups was in close contact with the enamel surface. These results suggested that the adhesion of the nano sealant used in this study was 
not affected by the application of fluoride varnish before etching. This finding may explain a lot the reduced microleakage observed in this study. These results are in agreement with the results of Wang and Sheen ${ }^{(11)}$, Kimura et $\mathrm{al}^{(13)}$, and Cheong et $\mathrm{al}^{(14)}$, who reported that the tensile strength of the sealant was not affected by the fluoride application before acid etching. However, it contradicts the results of Meng et $\mathrm{al}^{(12)}$ who reported that the fluoride application before acid etching negatively affected the retention of the sealants.

One of the most important factors for the success of sealants is the marginal integrity of the material which indicates absence of microleakage. The results of this study showed that there is no significant difference between the control and test groups regarding score 0 (no microleakage. This finding is matching with the previous studies of Mirkarimi et al.2012(26); Warran et al.2001 ${ }^{(27)}$; and Garcia-Goday et al. 1991 ${ }^{(28)}$.

These results revealed that the use of fluoride prior to sealant application does not increase microleakage. Microleakage test was done using $2 \%$ buffered methylene blue dye. It is believed that when a material behaves positively (no or little leakage) in in vitro tests using dye stain, it would behave more better clinically because the penetration of the dye material is much easier than the bacteria and bacterial product $^{(29)}$.

On the other hand, this result can be attributed to the type of sealant used in this study. The nano sealant has better adaptation than conventional one due to the addition of nano particles which allow the production of flowable material with better flow ability and surface tension, so it can penetrate deep into etched enamel ${ }^{(30)}$.

On the light of this study it can be concluded that application of fluoride did not affect the sealant application especially for the etching times 40 and 60 seconds.

\section{REFERENCES}

1- Haugejorden O, MagneBirkeland J. Ecological timetrendanalysis of caries experience at 12 years of age and caries incidence from age 12 to 18 years: Norway 1985 2004. Acta Odontologica Scandinavica 2006; 64: 368-75.

2- Dye BA, Tan S, Smith V, Lewis BG, Barker LK, ThorntonEvans G, et al. Trends in oral health status: United States, 1988-1994 and1999-2004. Vital and Health Statistics. Series 11, Data from the National Health Survey 2007; 248: 1-92.

3- Zahran MA. An epidemiological study to establish the prevalence of 3 oral diseases in Egyptian school children. Egypt Dent J 1962; 8:20-30.

4. Salama RI. An oral health survey in Damietta Center. Ph D thesis, Faculty of Dentistry, Mansoura University, Egypt, 2009.

5. Abo-bakr RM. Prevalence and severity of dental erosion and its relationship to dental caries and their associated risk indicators among a group of preparatory school pupils in Mansoura city. Ph D thesis. Faculty of Dentistry, Mansoura University, Egypt, 2012.

6- Batchelor PA, Sheiham A. Grouping of tooth surfaces by susceptibility to caries: a study in 5-16 year-old children. BMC Oral Health 2004; 4: 2.

7- Wendt LK, Koch G, Birkhed D. On the retention and effectiveness of fissure sealant in permanent molars after 1520 years: a cohort study. Community Dent Oral Epidemiol 2001; 29: 302 - 307.

8- Mok TB, McIntyre J, Hunt D: Dental erosion: in vitro model of wine assessor's erosion. Aust Dent J 2006; 46: 263-268.

9- Jones L, Lekkas D, Hunt D, McIntyre J, Rafir W: Studies on dental erosion: an in vivo-in vitro model of endogenous dental erosion-its application to testing protection by fluoride gel application. Aust Dent J 2002; 47: 304-308.

10- Whelton H, O'Mullane D. The use of combinations of caries preventive procedures. J Dent Educ 2001; 65: $1110-1113$.

11- Wang WN, Sheen DH: The effect of pretreatment with fluoride on the tensile strength of orthodontic bonding. Angle Orthod 1991; 61: 31-34.

12- Meng CL, Li CH, Wang WN: Bond strength with APF applied after acid etching. Am J Orthod Dentofacial Orthoped 1998; 114: 510-513. 
13- Kimura T, Dunn W, Taloumis L: Effect of fluoride varnish on the in vitro bond strength of orthodontic brackets using self-etching primer system. Am J Orthod Dentofacial Orthop 2004; 25: 351-356.

14- Cheong Y, Choi S, Kim S, Park H: Nanostructural effect of acid-etching and fluoride application on human primary and permanent tooth enamel. Materials Sien and Eng C 2012; 32: 1127-1132.

15- Al-Sugair MH, Akpata ES. Effect of fluorosis on etching of human enamel. J Oral Rehabil 1999; 26: 521-528.

16- Opinya GN, Pameiher CH. Tensile bond strength of fluorosed Kenyan teeth using the acid etch technique. Int Dent J 1986; 36: 225-229.

17- Gallegos T, Alonso V, Marin N, Castanon G, Anusavice $\mathrm{K}$, Rodriguez J:Enamel roughness and depth profile after phosphoric acid etching of health and fluorotic enamel. Aus Dent J 2012; 57: 151-157.

18. Ripa LW, Leske GS, Forte F. The combined use of pit and fissure sealants and fluoride mouthrinsing in second and third grade children: one-year clinical results. Pediatric dentistry 1986; 8: 158-162.

19. Manarelli MM, Delbem AC, Lima TM, Castilho FC, Pessan JP. In vitro reminralizing effect of fluoride varnishes containing sodium trimetaphosphate. Caries Res. 2014; 48: 299-305.

20. Al-Jobair A. Scanning electron microscope analysis of sealant penetration and adaptation in contaminated fissures. Journal of Indian Society of Pedodontics and Preventive Dentistry 2013; 31: 169-174.

21. Vanessa Pardi V. Sinhoreti MA., Pereira AC., Meneghim MC. An Vitro Evaluation of Microleakage of Different Materials Used as Pit-and-Fissure Sealants. Braz Dent J 2006; 17: 49-52.
22. Grande RH, Ballester R, Singer Jda M, Santos JF. Microleakage of a universal adhesive used as a fissure sealant. Am J Dent 1998; 11: 109-13 .

23. Swartz ML, Phillips RW, Norman RD, Elliason S, Rhodes BF, Clark HE. Addition of fluoride to pit and fissure sealants-a feasibility study. J Dent Res 1976; 55: 757-771.

24- Kukiattrakoon B, Thammasitboon K. The effect of different etching times of acidulated phosphate fluoride gel on shear bond strength of high leucite ceramics bonded to composite resin. J Proth Dent 2007; 98: 17-23.

25- Choi S, Rhee Y, Park J, Lee G, Kim K, Park Y, Park H. Effects of fluoride treatment on phosphoric acid-etching in primary teeth: An AFM Observation. Micron 41, 2010; 498-506.

26- Mirkarimi M, Beheshti M, Mahmoudi F. Microleakage assessment of pit and fissure sealants with previous fluoride application: an in vitro study. Res J Med Sci 2012; 6: $22-25$.

27- Warren DP, Infant NB, Rice HC, Turner SD, Chan JT. Effect of topical fluoride on retention of pit and fissure sealants. J Dent Hyg 2001; 75:21-24.

28- Garcia- Godoy F, Perez R, Hubbard GW. Effect of prophylaxis pastes on shear bond strength. J Clin Orthod 1991; 25: 571-573.

29- Toman MS, Toksavul C, Artunc M, Turkun PS, Nergiz I. Influence of luting agent on microleakage of all-ceramic crowns. J Adehs Den 2007; 9: 39-47.

30- Kervanto S. Lavonius E. Pietila I. Pitkaniemi J. Meurman J. Kerosuo E. Comparing the caries preventive effect of two fissure sealant modalities in public health care. Int $\mathrm{J}$ Paediatr Dent 2008; 18: 56-61. 